\title{
Mechanisms of Cardiovascular Aging
}

\author{
Francesco Paneni • Sarah Costantino • \\ Francesco Cosentino • Thomas Felix Lüscher
}

Published online: 9 October 2013

(C) Springer Science+Business Media New York 2013

\begin{abstract}
Aging is a major driver of cardiovascular (CV) disease. Incidence of stroke and myocardial infarction increases, and is associated with worsening outcomes, in relation to patient age. Therefore, by studying chronological age in relation to other $\mathrm{CV}$ risk factors, pertinent mechanisms of senescence and disease in the heart and blood vessels can be delineated. This is a rather complex process that entails activation of detrimental molecular pathways. An emerging science is revealing intricate signalling cascades which may explain why cardiac and vascular aging are accelerated in the context of CV risk factors. The identification of novel molecular pathways may provide critical insights for mechanism-based therapeutic strategies to prevent premature aging and related CV disease burden. Our lab, as well as other investigators, has recently identified aging and longevity genes and their participation to early vascular and cardiac disease. In the present review, we discuss recent advances in the pathophysiology of agerelated vascular and myocardial disease: i) altered nitric oxide signalling as a determinant of vascular and microvascular dysfunction; ii) determinants of mitochondrial oxidative stress; iii) emerging links between oxidant and
\end{abstract}

\footnotetext{
F. Paneni $\cdot$ S. Costantino $\cdot$ F. Cosentino $\cdot$ T. F. Lüscher Cardiology, University Heart Center and Cardiovascular Research, Institute of Physiology and University Hospital, Zürich, Switzerland

F. Cosentino

Cardiology, Department of Clinical and Molecular Medicine,

University of Rome "Sapienza", Rome, Italy

T. F. Lüscher

Zürich Center for Integrative Human Physiology (ZIHP),

University of Zürich, Zürich, Switzerland

F. Paneni $(\bowtie)$

Cardiovascular Research, Institute of Physiology, University of

Zürich, CH-8057 Zurich, Switzerland

e-mail: francesco.paneni@gmail.com
}

inflammatory genes; and iv) mechanisms of endothelial and cardiac progenitor cell dysfunction as well as therapeutic implications for vascular and myocardial repair. Such a mechanistic overview illuminates attractive molecular targets for the prevention of age-driven pathology in the vasculature and the heart.

Keywords Aging $\cdot$ Oxidative stress $\cdot$ Mitochondria $\cdot \mathrm{CV}$ disease

\section{Introduction}

Age is one of the major risk factors associated with cardiovascular disease [1]. Aging of the heart and vessels is a rather complex process ensuing in the deterioration of tissue structure and functionality [2]. Time-dependent changes occurring in the $\mathrm{CV}$ system are certainly aggravated by concomitant risk factors such as hypertension, smoking and diabetes [3]. Indeed, clustering of these conditions anticipates physiological aging, resulting in early features of cardiac and vascular senescence [4]. The synergic effect of aging and other risk factors is an important driver of myocardial infarction, stroke and CV death. Indeed, available heart age calculators include common modifiable and non-modifiable risk factors [5]. These tools are being widely used among the general population and may help to monitor and eventually improve individual $\mathrm{CV}$ health status. In the absence of other risk factors or $\mathrm{CV}$ disease, the heart age of a 30-year-old man who smokes is six years higher than expected. Such an example confirms that risk factors precipitate $\mathrm{CV}$ aging. Therefore, the term "aging" may be misinterpreted since it refers only to the "passage of time". Conversely, aging of the heart and vessels is driven by challenging factors and should be considered as a picture of global CV risk. Although experimental 
studies have shown that aging per se triggers endothelial dysfunction and atherosclerosis [6], it remains difficult to understand its real impact since $\mathrm{CV}$ risk factors advance as time goes by.

\section{Pathological Features of Cardiovascular Aging}

Clinical and pre-clinical data have shown that aging is associated with structural and functional properties of large arteries [7, 8]. In aged healthy humans these alterations are represented by luminal dilation, increased arterial stiffness, endothelial dysfunction and diffuse intimal thickening. Elastic proximal arteries such as the central aorta and the carotid artery dilate with age, resulting in increased lumen diameter. Aging also leads to a progressive thickening of the media with subsequent vascular stiffness. Increased stiffness may be the result of different factors including enhanced elastin degradation and collagen deposition in the vascular media $[9,10]$. Importantly, remodelling of the vasculature is accompanied by key alterations of endothelial homeostasis. Occurrence of endothelial dysfunction is a major cause of morbidity and mortality [11]. Seminal studies have clearly shown that endothelium-dependent vasorelaxation is impaired in aged vessels and this phenomenon is associated with increased vascular permeability and inflammation as well as impaired angiogenesis (see Fig. 1) $[6,12-14]$. The endothelial layer is an active tissue orchestrating a fine balance between vasodilating and vasoactive factors [15]. Age-related alterations of endothelial cell functionality may, in turn, aggravate media thickness and vascular fibrosis. Beside abnormalities of the vascular bed, the aging process certainly affects heart structure and function [16]. Heart weight increases with age, regardless of blood pressure values. By contrast, the number of cardiac myocytes progressively decreases, suggesting that hypertrophy and fibrosis are major hallmarks of the aged heart. This continued loss of functional cardiac cells is paralleled by a decline in regenerative activity from $1 \%$ per year at age 20 to $0.4 \%$ at 75 years [17]. Fibrosis in the aged myocardium serves as a pathological substrate for potential arrhythmias, namely atrial fibrillation. An important pathological feature associated with aging is the calcification of aortic and mitral valves which triggers stenosis/insufficiency resulting in cardiac pressure/volume overload. Moreover, the number of cells in the sino-atrial node decreases and this explains chronotropic incompetence in response to maximum exercise. Such age-dependent decline of cardiac functional reserve may predispose elderly people to heart failure [18]. Myocardial fibrosis and stiffness concur to the impairment of left ventricular compliance, leading to a pre-clinical decline of diastolic and systolic function [19].

\section{Nitric Oxide as a Determinant of Vascular and Microvascular Function}

Nitric oxide (NO) is the most important vasodilator produced by endothelial NO synthase (eNOS) and is a marker of vascular health [20]. Indeed, reduced NO bioavailability is a strong predictor of CV events [21]. Impaired NO bioavailability is observed in hypertension, diabetes and atherosclerosis [22, 23]. Notably, experimental and human studies have shown that aging leads to reduced NO production and endothelial dysfunction, regardless of other risk factors [24, 25 • , $26,27]$. Aging may impair eNOS functionality via several mechanisms [10]. A deficiency in eNOS substrates and cofactors plays a pivotal role.

L-arginine, a major eNOS substrate, is rapidly degraded by arginase II, leading to decreased substrate availability and reduced NO synthesis [28]. Interestingly, arginase II activity and expression increase with age, thus contributing to endothelial dysfunction in this setting [29]. Arginase II may represent an attractive target for the prevention of age-related endothelial dysfunction since a recent study showed that arginase inhibition improves brachial artery vasodilation in diabetic subjects [30]. Pharmacological suppression of arginase activity may indeed restore physiological substrate levels and improve vascular functionality in elderly individuals (see Fig. 1). Very recently, arginase II upregulation has shown to mediate age-related decrease of the cardiac contractile reserve [31]. This latter observation suggests a potential role of arginase inhibition also for the prevention of heart failure.

Beside L-arginine, tetrahydrobiopterin (BH4) is an important cofactor for eNOS activity involved in age-related endothelial dysfunction (see Fig. 1) [28]. Indeed, increased oxidative stress rapidly degrades $\mathrm{BH} 4$ resulting in altered eNOS efficiency whereas exogenous administration improves endothelium-dependent vasodilation in human aging [32]. Moreover, Akt-dependent eNOS active phosphorylation at Ser1177 is significantly reduced in aged vessels and accounts for impaired vasorelaxation in large arteries as well as in the collateral circulation [1].

Alteration of eNOS transcription may be also involved in endothelial dysfunction but its biological significance remains unclear. Many studies found increased eNOS expression in aging [14] and such an observation has been interpreted as a compensatory but futile mechanism to counterregulate the loss of NO [14]. Preservation of NO signalling is required for the maintenance of coronary microvascular function, an important determinant of myocardial viability and energetics [33]. Age-dependent alterations at the level of the coronary circulation may play an important role in the evolution of left ventricular fibrosis and function. Indeed, age-related eNOS dysfunction is critically involved in microvascular dysfunction and impaired ventricular contractility in elderly patients [34]. 


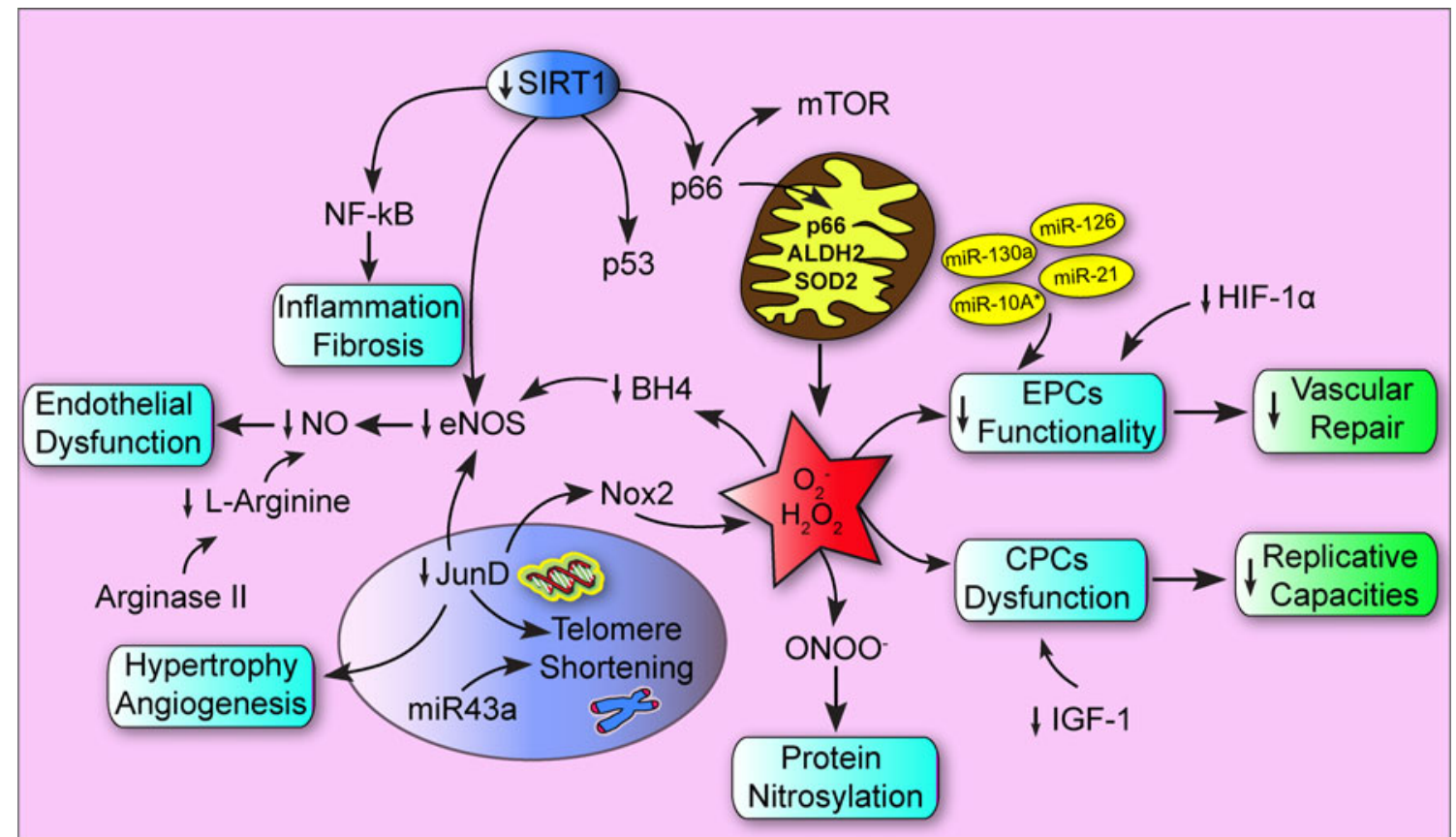

Fig. 1 Schematic representation of molecular pathways involved in agerelated vascular and myocardial dysfunction. NO, nitric oxide; eNOS, endothelial nitric oxide synthase; $\mathrm{BH} 4$, tetrahydrobiopterin; miR,
microRNA; IGF-1, insulin like growth factor-1; NF-kB, nuclear factorkappa B; HIF1- $\alpha$, hypoxia inducible factor $1-\alpha, \mathrm{ONOO}^{-}$, peroxynitrite; EPCs, endothelial progenitor cells; CPC, cardiac progenitor cells
Advanced age is also associated with decreased angiographic presence of collaterals to the infarct-related artery in patients with acute myocardial infarction. This abnormality may contribute to the poor prognosis of elderly patients with acute coronary syndromes [35]. Collectively, this evidence strongly suggests that modulation of eNOS functionality is a promising target for the prevention of age-related vascular disease (see Fig. 1).

\section{Mitochondrial Reactive Oxygen Species}

A major feature of $\mathrm{CV}$ aging is the imbalance between $\mathrm{NO}$ bioavailability and accumulation of reactive oxygen species (ROS) [14], leading to endothelial dysfunction [36, 37]. Indeed, age-dependent generation of the superoxide anion $\left(\mathrm{O}_{2}{ }^{-}\right)$ inactivates $\mathrm{NO}$ to form peroxynitrite $\left(\mathrm{ONOO}^{-}\right)$, a powerful oxidant which easily penetrates across phospholipid membranes and induces substrate nitration [14]. Protein nitrosylation blunts activity of antioxidant enzymes and endothelial NO synthase [38]. Generation of ROS into the vessel wall has been postulated as a major pathophysiological step favouring aging of arteries [1]. Among the different aging theories, the mitochondrial free radical theory of aging has taken center stage for several decades. According to this assumption, ROS are considered to be a detrimental toxic bioproduct of aerobic metabolism that induce oxidative cellular damage due to their high chemical reactivity. ROS are small molecules highly reactive because of the presence of unpaired electrons. They are generated within the cell as byproducts of several metabolic and enzymatic pathways. However, the majority of cellular ROS are generated within the mitochondrial oxidative phosphorylation. During this process, electrons are extracted from NADH and FADH and transferred to molecular oxygen through a chain of four enzymatic complexes ensuring phosphorylation of ADP in ATP and final reduction of molecular oxygen to water [6]. Indeed, electrons derived from NADH or FADH can directly react with oxygen or other electron acceptors within the mitochondrial electron transport chain and generate free radicals. Accumulation of ROS causes mitochondrial disruption leading to cytochrome $c$ release and subsequent activation of caspase 3 [37]. CV risk factors such as hyperglycemia induce a ROS-dependent alteration of the mitochondrial network resembling early signs of vascular aging [39]. Indeed, endothelial cells isolated from middle-age diabetic subjects show a premature derangement of organelle structure which correlated with impaired flow mediated vasodilation of the brachial artery [39].

\section{Vascular and Cardiac Effects of Aging and Longevity Genes}

Mitochondrial Adaptor p66 ${ }^{\text {Shc }}$

Given the importance of oxidative signals in the biology of vascular aging, it is important to elucidate the molecular machineries involved in such a phenomenon. In recent years 
several oxidative genes have been identified in the etiologic pathway linking aging and CV disease. Intracellular free radicals are reduced in cells lacking the $\mathrm{p} 66^{\mathrm{Shc}}$ gene $\left(\mathrm{p} 66^{\mathrm{Shc}-/-}\right.$ cells), and both systemic as well as intracellular free radicals are diminished in $\mathrm{p} 66^{\mathrm{Shc}-1-}$ mouse models exposed to high oxidative stress.[6]. The $\mathrm{p} 66^{\mathrm{Shc}}$ adaptor protein functions as a redox enzyme implicated in mitochondrial ROS generation and translation of oxidative signals into apoptosis (see Fig. 1) $[6,24,40-42]$.

Several chronic stimuli activate the protein kinase C BII (PKC $\beta \mathrm{II}$ ) isoform to induce Ser-36 phosphorylation of p66 ${ }^{\text {Shc }}$, allowing transfer of the protein from the cytosol to the mitochondrion where it catalyzes ROS production via cytochrome c oxidation [42]. This latter event leads to mitochondrial disruption and cell death. Indeed, increased ROS generation alters mitochondrial permeability facilitating the release of intermembrane space proapoptotic proteins such as cytochrome $c$ [42]. Once released in the cytosol, cytochrome $c$ is responsible for activation of the apoptosis execution enzyme caspase. Accordingly, mice lacking the $\mathrm{p} 66^{\text {Shc }}$ gene $\left(\mathrm{p} 66^{\mathrm{Shc}-/}\right.$ ) display a prolonged lifespan, increased resistance to oxidative stress, and apoptosis.

We have previously reported that endothelium-dependent relaxation in response to acetylcholine was age-dependently impaired in WT mice but not in $\mathrm{p} 66^{\mathrm{Shc}-1-}$ mice [24]. Accordingly, $\mathrm{p} 66^{\text {Shc- }-1}$ mice were protected against the age-related decline of NO release. This study suggests that $\mathrm{p} 66^{\text {Shc }}$ signalling is required to induce a ROS-driven vascular senescent phenotype.[24]. Importantly, $\mathrm{p} 66^{\text {Shc }}$ activation is thought to be upstream of NADPH as well as a mammalian target of the rapamycin (mTOR) pathway, two important determinants of vascular damage [43-45].

Activation of $\mathrm{p} 66^{\mathrm{Shc}}$ also interferes with the progression into the senescent heart phenotype and the development of heart failure in diabetic mice [46]. Indeed, diabetic p $66^{\text {Shc- }--}$ mice were protected against myocardial oxidative stress, apoptosis and telomere shortening [46]. Moreover, ablation of the p $66^{\text {Shc }}$ gene in cardiac stem cells preserved the growth reserve of the heart [46]. Although these studies provide interesting insights into the role of $\mathrm{p} 66^{\text {Shc }}$ in CV aging, it remains unclear whether protein inhibition may reverse vascular disease phenotype. In this regard, we have demonstrated for the first time that in vivo RNA interference blunts vascular p $66^{\text {Shc }}$ expression, ROS generation and endothelial dysfunction in diabetic mice [47]. Our findings suggest that $\mathrm{p} 66^{\text {Shc }}$ inhibition may prevent or delay the development of age-related CV disease such as myocardial infarction and stroke.

The clinical relevance of $\mathrm{p} 66^{\mathrm{Shc}}$ is supported by the notion that $\mathrm{p} 66^{\text {Shc }}$ gene expression is increased in mononuclear cells obtained from patients with type 2 diabetes and coronary artery disease $[48,49]$. A recent study showed that $\mathrm{p} 66^{\text {Shc }}$ expression is higher in fibroblasts isolated from centenarians [50]. This finding likely indicates that $\mathrm{p} 66^{\mathrm{Shc}}$ expression may increase in a time-dependent manner. By contrast, early gene upregulation due to risk factors may anticipate features of $\mathrm{CV}$ aging in middle-age individuals [51].

Transcription Factor JunD Regulates Oxidant and Scavenger Enzymes

The Activated Protein-1 (AP) transcription factor JunD is emerging as an important modulator of age-driven mitochondrial oxidative stress [52]. AP-1 is a collection of dimeric complexes made by different members of three families of DNA-binding proteins: Jun, Fos, and ATF/CREB [53]. These members assemble to form AP-1 transcription factors with activities that are strongly influenced by their specific components and their cellular environment. JunD, the most recent gene of the Jun family, regulates cell growth and survival and protects against oxidative stress by modulating genes involved in antioxidant defense and ROS production [54]. Our recent work has shown that in contrast with $\mathrm{p} 66^{\text {She }}$, JunD is a longevity gene implicated in the preservation of vascular homeostasis during life [25••]. We found that JunD is downregulated by aging both in the mouse aorta and in peripheral monocytes of old as compared with young healthy individuals $[25 \bullet \cdot]$.

Young JunD ${ }^{-1-}$ mice showed early endothelial dysfunction and vascular senescence, which were comparable with the one observed in aged WT mice. JunD deletion was indeed associated with upregulation of the aging markers p53 and p $16^{\mathrm{INK} 4 \mathrm{a}}$, reduced telomerase activity and mitochondrial DNA damage $[25 \bullet \cdot$. Interestingly enough, transient overexpression of JunD was able to rescue endothelial dysfunction in aged mice. Mechanistically, we found that JunD is required for the expression of mitochondrial antioxidant enzymes such as manganese superoxide dismutase and aldehyde dehydrogenase 2 (ALDH-2, see Fig. 1). This latter enzyme was almost abolished in young $\mathrm{JunD}^{-/}$mice compared with age-matched littermates. The relevance of this finding is supported by the notion that ALDH-2 protects against ischemia/ reperfusion injury [55] and cardiac arrhythmias [56].

Moreover, JunD participates to eNOS transcription, thus contributing to preserved NO availability during aging [57]. The transcription factor also modulates the expression and activity of NADPH oxidase in the vasculature [25••]. Indeed, $\mathrm{JunD}^{-/-}$mice display a premature upregulation of NADPH isoform p47phox, Nox2 and Nox4 leading to increased vascular oxidative stress already in early stages of life. Moreover, in our study JunD expression negatively correlated with NADPH subunits in aged individuals. In line with our findings, the lack of JunD promotes pressure overload-induced apoptosis, hypertrophic growth, and angiogenesis in the heart [58]. Notably, JunD protein levels are decreased in patients with end-stage heart failure suggesting that the transcription factor may protect against age-related cardiac dysfunction 
[59]. Based on these recent observations on the role of $\mathrm{p} 66^{\text {Shc }}$ and JunD in aging, one can postulate that early deregulation of aging and longevity genes may anticipate $\mathrm{CV}$ senescence (see Fig. 1). The importance of premature senescence in this setting is strengthened by the notion that myocardial infarction and stroke exhibit a strong age dependency [4].

\section{Mammalian Deacetylase SIRT1}

The family of nicotinamide adenine dinucleotide (NAD)-dependent proteins termed sirtuins has recently emerged as an important regulator of $\mathrm{CV}$ aging. SIRT1 is considered a major gatekeeper against oxidative stress and tissue inflammation [60]. Increased SIRT1 activity confers resistance to many of the CV sequelae associated with aging [61]. In the heart, SIRT1 overexpression leads to reduced myocardial hypertrophy, interstitial fibrosis, oxidative stress and senescent markers such as $\mathrm{p} 15^{\mathrm{INK} 4 \mathrm{~b}}$ and $\mathrm{p} 19^{\mathrm{ARF}}$ [62]. Moreover, activation of SIRT1 in endothelial tissues may be of benefit in preserving endothelial cell function during aging [63]. Mice with endothelial specific SIRT1 overexpression on an $\mathrm{ApoE}^{-/-}$ genetic background exhibit attenuated development of atherosclerotic lesions [64]. Conversely, SIRT1 insufficiency results in greater foam cell formation and atherosclerosis [65]. In the human endothelium, overexpression of SIRT1 prevents oxidative stress-induced senescence, while its inhibition leads to a premature senescence-like phenotype. Interestingly, immunosuppressant drugs, like sirolimus and everolimus, induce endothelial cellular senescence via SIRT1 downregulation [66]. SIRT1 inhibition also impairs eNOS functionality whereas its activation improves endothelial NO availability [63]. Hence, the SIRT1/NO axis may represent a relevant target against vascular and cardiac senescence.

SIRT1-mediated deacetylation modulates the function of proteins via transcriptional and post-translational changes. A recent study reported that vascular $\mathrm{p} 66^{\mathrm{Shc}}$ gene transcription may be the result of decreased promoter deacetylation due to downregulation of SIRT1 [67•]. Therefore, one can certainly postulate that SIRT1 and $\mathrm{p} 66^{\text {Shc }}$ stand along the same molecular pathway involved in the modulation of vascular and myocardial integrity during aging (see Fig. 1). Moreover, both SIRT1 and $066^{\text {Shc }}$ lie upstream and downstream the tumour suppressor p53, critically involved in age-dependent mitochondrial disruption and apoptosis (see Fig. 1) [63]. Downregulation of SIRT1 also favours increased acetylation of nuclear factor (NF)-kB p65, leading to its nuclear translocation and transcription of inflammatory genes [63].

\section{Nuclear Factor-kB p65}

$\mathrm{NF}-\mathrm{kB}$ is an important transcription factor expressed in all mammalian cell types. It is responsible for regulating the gene expression of factors that control cell adhesion, proliferation, inflammation, redox state, and tissue specific enzymes [60]. Activation of NF-kB mediates vascular and myocardial inflammation in metabolic and age-related diseases [68]. A recent study clearly demonstrated that endothelial suppression of NF-kB prolongs lifespan in mice and ameliorates obesityinduced endothelial insulin resistance [69••].

Impaired insulin signalling is indeed an important hallmark linking metabolic disease with premature aging of the $\mathrm{CV}$ system [23]. The relevance of these findings is supported by the notion that NF- $\mathrm{KB}$ protein is elevated in vascular endothelial cells isolated from obese and aged adults as compared with normal weight and young controls [70]. Moreover, agedependent $\mathrm{NFKB}$ activation was associated with systemic inflammation and impaired endothelial dependent dilation [71]. NF-kB is also a potent mediator of age-induced myocardial inflammation and fibrosis. Accordingly, NF-kB suppression, using direct gene delivery of short hairpin p65 RNA, attenuates remodelling and cardiac hypertrophy [72]. These data validate NF-kB as a therapeutic target to prevent cardiac disease in elderly (see Fig. 1).

\section{Vascular and Myocardial Repair in Aging: Mechanistic and Therapeutic Insights}

Recovery after ischemia or infarction in any organ requires blood vessel growth [73]. The incidence of stroke, claudication and myocardial infarction all increase in elderly patients, and they have worse outcomes when ischemia and infarction does occur. Capillary density as well as angiogenic response are impaired in aged individuals [73]. In this context, senescence of endothelial progenitor cells (EPCs) and early angiogenic outgrowth cells (EOCs) [74] are especially relevant. These cell types significantly contribute to endothelial repair, a phenomenon which is less efficient in aging [75].

EPCs are thought to directly mediate endothelial regeneration while EOCs represent an heterogeneous pool of cell precursors, mostly of myeloid origin, which favour endothelial healing via a paracrine mechanism [76]. Although we are still far from a clear understanding of these processes, available knowledge support the notion that aging impairs the function of ex-vivo expanded EPCs [77]. Age-related EPC dysfunction is mediated by the imbalance between factors promoting growth, migration/survival and those enhancing oxidative stress/senescence [75]. Hypoxia inducible factor $1 \alpha(\mathrm{HIF}-1 \alpha)$ induces the expression of stromal cell-derived factor 1 (SDF-1) that enhances the recruitment of EPCs in injured or ischemic tissues in mice. HIF- $1 \alpha / \mathrm{SDF}-1$ signalling is impaired in aging and contributes to altered vascular repair (see Fig. 1) [78].

Interestingly, $\mathrm{CV}$ risk factors mirror the aging process by impairing EPCs functionality and, hence, the vascular repair process $[79,80]$. Indeed, the aging gene $\mathrm{p} 66^{\mathrm{Shc}}$ is upregulated 
in EPCs isolated from diabetic subjects and contributes to impaired migration and tube formation [81]. By contrast, vascular repair capacities are preserved in EPCs isolated from p66 ${ }^{\mathrm{Shc}-/-}$ diabetic mice [81].

Recent work suggests that microRNAs (miRs) may be involved in the pathogenesis of age-related EPCs dysfunction (see Fig. 1) [82, 83]. These small non-coding RNAs orchestrate EPCs functionality by regulating gene expression at the post-transcriptional level [84]. In order to map the microRNA/gene expression signatures of EPCs senescence, Zhu and colleagues performed a microRNA profiling and microarray analysis in lineage-negative bone marrow cells from young and aged wild-type as well as $\mathrm{ApoE}^{-/}$mice $[85 \bullet \cdot$. Their analysis found miR-10A* and miR-21, and their common target gene Hmga2, as critical regulators of EPCs senescence. Indeed, overexpression of miR-10A* and miR-21 in young EPCs suppressed Hmga2 expression, leading to increased $\mathrm{p} 16^{\mathrm{INK} 4 \mathrm{a}} / \mathrm{p} 19^{\mathrm{ARF}}$ expression and impaired EPC angiogenesis in vitro and in vivo. In contrast, suppression of miR-10A* and miR-21 in aged EPCs increased Hmga2 expression and rejuvenated EPCs, thus improving angiogenesis [85••]. Furthermore, miR-34a was found to inhibit EPCmediated angiogenesis by inducing senescence via suppressing SIRT1 [86].

A recent study from our group showed that reprogramming angiomiR-126 and -130a in angiogenic EOCs and circulating EPCs isolated from patients with heart failure improve cardiac function and vascular repair in mice [87]. These novel data suggest the possibility that in vitro reprogramming of human EPCs may improve vascular repair. Such an observation deserves attention since intracoronary administration of autologous bone marrow-derived mononuclear cells has failed to improve cardiac function in patients with myocardial infarction (MI) [88].

Cardiac progenitor cells (CPC) are also critically involved in growth and myocyte formation to compensate myocyte loss due to prolonged ischemia [89]. Seminal observations have showed clearly the potential of CPC in preventing adverse cardiac remodelling and failure during myocardial ischemia [90]. Aging causes CPC dysfunction mostly affecting their replicative capacities. In this regard, early loss of Insulin like growth factor-1 (IGF-1) plays a pivotal role (see Fig. 1) [91, 92]. A recent study showed that chronological age was a major predictor of five biomarkers of human CPC senescence: telomeric shortening, attenuated telomerase activity, and telomere dysfunction-induced foci as well as $\mathrm{p} 21^{\mathrm{Cip} 1}$ and $\mathrm{p} 16^{\mathrm{INK} 4 \mathrm{a}}$ expression [93]. The preliminary findings of the SCIPIO trial suggest that intracoronary infusion of autologous CPC is effective in improving LV systolic function and reducing infarct size in patients with heart failure after myocardial infarction [94]. These encouraging findings provide glimpses for myocardial regeneration in elderly patients with myocardial infarction.

\section{Conclusions}

Multiple molecular mechanisms are implicated in early CV aging and disease. Premature activation of aging genes such as p $66^{\text {Shc }}$ and NF-kB as well as downregulation of lifespan determinants JunD and SIRT1 may trigger senescence features, leading to early $\mathrm{CV}$ disease. Dysregulation of aging and longevity after a life-time course to CV risk factors support the reprogramming of endothelial and cardiac stem cells as a promising strategy to delay the onset and progression of $\mathrm{CV}$ disease.

Acknowledgments Research discussed in this manuscript was supported by the Swiss National Research Foundation (to T.F.L. Nr. 3100 068118.02/1), the Swiss Heart Foundation (to F.C.) and the Foundation for Cardiovascular Research - Zurich Heart House, Zurich, Switzerland.

\section{Compliance with Ethics Guidelines}

Conflict of Interest Francesco Paneni declares that he has no conflict of interest.

Sarah Costantino declares that she has no conflict of interest.

Francesco Cosentino declares that he has no conflict of interest.

Thomas Felix Lüscher declares that he has no conflict of interest.

Human and Animal Rights and Informed Consent This article does not contain any studies with human or animal subjects performed by any of the authors.

\section{References}

Papers of particular interest, published recently, have been highlighted as:

- Of importance

-• Of major importance

1. Kovacic JC, Moreno P, Hachinski V, Nabel EG, Fuster V. Cellular senescence, vascular disease, and aging: part 1 of a 2-part review. Circulation. 2011;123:1650-60.

2. Olivieri F, Recchioni R, Marcheselli F, Abbatecola AM, Santini G, Borghetti G, et al. Cellular senescence in cardiovascular diseases: potential age-related mechanisms and implications for treatment. Curr Pharm Des. 2013;19:1710-9.

3. Laurent S. Defining vascular aging and cardiovascular risk. J Hypertens. 2012;30(Suppl):S3-8.

4. Kovacic JC, Moreno P, Nabel EG, Hachinski V, Fuster V. Cellular senescence, vascular disease, and aging: part 2 of a 2-part review: clinical vascular disease in the elderly. Circulation. 2011;123:1900 10.

5. Allan GM, Nouri F, Korownyk C, Kolber MR, Vandermeer B, McCormack J. Agreement among cardiovascular disease risk calculators. Circulation. 2013;127:1948-56.

6. Cosentino F, Francia P, Camici GG, Pelicci PG, Luscher TF, Volpe M. Final common molecular pathways of aging and cardiovascular disease: role of the p66Shc protein. Arterioscler Thromb Vasc Biol. 2008;28:622-8. 
7. Nilsson PM, Boutouyrie P, Laurent S. Vascular aging: a tale of EVA and ADAM in cardiovascular risk assessment and prevention. Hypertension. 2009;54:3-10.

8. Laurent S, Alivon M, Beaussier H, Boutouyrie P. Aortic stiffness as a tissue biomarker for predicting future cardiovascular events in asymptomatic hypertensive subjects. Ann Med. 2012;44 Suppl 1: S93-7.

9. Najjar SS, Scuteri A, Lakatta EG. Arterial aging: is it an immutable cardiovascular risk factor? Hypertension. 2005;46:454-62.

10. Virdis A, Ghiadoni L, Giannarelli C, Taddei S. Endothelial dysfunction and vascular disease in later life. Maturitas. 2010;67:20-4.

11. Flammer AJ, Anderson T, Celermajer DS, Creager MA, Deanfield J, Ganz P, et al. The assessment of endothelial function: from research into clinical practice. Circulation. 2012;126:753-67.

12. Camici GG, Shi Y, Cosentino F, Francia P, Luscher TF. Anti-aging medicine: molecular basis for endothelial cell-targeted strategies - a mini-review. Gerontology. 2011;57:101-8.

13. Kung CF, Luscher TF. Different mechanisms of endothelial dysfunction with aging and hypertension in rat aorta. Hypertension. 1995;25: 194-200.

14. van der Loo B, Labugger R, Skepper JN, Bachschmid M, Kilo J, Powell JM, et al. Enhanced peroxynitrite formation is associated with vascular aging. J Exp Med. 2000;192:1731-44.

15. Brunner H, Cockcroft JR, Deanfield J, Donald A, Ferrannini E, Halcox J, et al. Endothelial function and dysfunction. Part II: association with cardiovascular risk factors and diseases. A statement by the Working Group on Endothelins and Endothelial Factors of the European Society of Hypertension. J Hypertens. 2005;23:233-46.

16. Kajstura J, Rota M, Urbanek K, Hosoda T, Bearzi C, Anversa P, et al. The telomere-telomerase axis and the heart. Antioxid Redox Signal. 2006;8:2125-41.

17. Sussman MA, Anversa P. Myocardial aging and senescence: where have the stem cells gone? Annu Rev Physiol. 2004;66: 29-48.

18. Dai DF, Chen T, Johnson SC, Szeto H, Rabinovitch PS. Cardiac aging: from molecular mechanisms to significance in human health and disease. Antioxid Redox Signal. 2012;16:1492-526.

19. Sciarretta S, Paneni F, Palano F, Chin D, Tocci G, Rubattu S, et al. Role of the renin-angiotensin-aldosterone system and inflammatory processes in the development and progression of diastolic dysfunction. Clin Sci (Lond). 2009;116:467-77.

20. Flammer AJ, Luscher TF. Three decades of endothelium research: from the detection of nitric oxide to the everyday implementation of endothelial function measurements in cardiovascular diseases. Swiss Med Wkly. 2010;140:w13122.

21. Lerman A, Zeiher AM. Endothelial function: cardiac events. Circulation. 2005;111:363-8.

22. Spieker LE, Flammer AJ, Luscher TF. The vascular endothelium in hypertension. Handb Exp Pharmacol. 2006;249-283.

23. Paneni F, Beckman JA, Creager MA, Cosentino F. Diabetes and vascular disease: pathophysiology, clinical consequences, and medical therapy: part I. Eur Heart J. 2013;doi:10.1093/eurheartj/eht149.

24. Francia P, delli Gatti C, Bachschmid M, Martin-Padura I, Savoia C, Migliaccio E, et al. Deletion of p66shc gene protects against agerelated endothelial dysfunction. Circulation. 2004;110:2889-95.

25. •- Paneni F, Osto E, Costantino S, Mateescu B, Briand S, Coppolino $\mathrm{G}$, et al. Deletion of the activated protein-1 transcription factor JunD induces oxidative stress and accelerates age-related endothelial dysfunction. Circulation. 2013;127:1229-40. This study demonstrates for the first time that AP-1 component JunD is critically involved in age-related vascular dysfunction. In aged mice and humans JunD is downregulated favouring alterations of oxidant enzymes, mitochondrial dysfunction and telomerase deregulation. Interestingly, reactivation of JunD in aged vessels rescues age-driven endothelial dysfunction, indicating that the transcription factor is required for the maintenance of vascular homeostasis during life.
26. Taddei S, Virdis A, Ghiadoni L, Salvetti G, Bernini G, Magagna A, et al. Age-related reduction of $\mathrm{NO}$ availability and oxidative stress in humans. Hypertension. 2001;38:274-9.

27. Tschudi MR, Barton M, Bersinger NA, Moreau P, Cosentino F, Noll $\mathrm{G}$, et al. Effect of age on kinetics of nitric oxide release in rat aorta and pulmonary artery. J Clin Invest. 1996;98:899-905.

28. Cosentino F, Luscher TF. Tetrahydrobiopterin and endothelial nitric oxide synthase activity. Cardiovasc Res. 1999;43:274-8.

29. Shin WS, Berkowitz DE, Ryoo SW. Increased arginase II activity contributes to endothelial dysfunction through endothelial nitric oxide synthase uncoupling in aged mice. Exp Mol Med. 2012;44:594-602.

30. Shemyakin A, Kovamees O, Rafnsson A, Bohm F, Svenarud P, Settergren M, et al. Arginase inhibition improves endothelial function in patients with coronary artery disease and type 2 diabetes mellitus. Circulation. 2012;126:2943-50.

31. Khan M, Steppan J, Schuleri KH, Ryoo S, Tuday E, Bugaj L, et al. Upregulation of arginase-II contributes to decreased age-related myocardial contractile reserve. Eur J Appl Physiol. 2012;112:2933-41.

32. Higashi Y, Sasaki S, Nakagawa K, Kimura M, Noma K, Hara K, et al. Tetrahydrobiopterin improves aging-related impairment of endothelium-dependent vasodilation through increase in nitric oxide production. Atherosclerosis. 2006;186:390-5.

33. Camici PG, Crea F. Coronary microvascular dysfunction. N Engl J Med. 2007;356:830-40.

34. O'Rourke MF, Safar ME, Dzau V. The cardiovascular continuum extended: aging effects on the aorta and microvasculature. Vasc Med. 2010;15:461-8

35. Kurotobi T, Sato H, Kinjo K, Nakatani D, Mizuno H, Shimizu M, et al. Reduced collateral circulation to the infarct-related artery in elderly patients with acute myocardial infarction. J Am Coll Cardiol. 2004;44:28-34

36. Bratic A, Larsson NG. The role of mitochondria in aging. J Clin Invest. 2013;123:951-7.

37. Kluge MA, Fetterman JL, Vita JA. Mitochondria and endothelial function. Circ Res. 2013;112:1171-88.

38. Cosentino F. Statins in cardiovascular disease. Role of Rho/Rho kinase inhibition and of Akt activation. Recenti Prog Med. 2003;94:444-50.

39. Shenouda SM, Widlansky ME, Chen K, Xu G, Holbrook M, Tabit $\mathrm{CE}$, et al. Altered mitochondrial dynamics contributes to endothelial dysfunction in diabetes mellitus. Circulation. 2011;124:444 53.

40. Camici GG, Schiavoni M, Francia P, Bachschmid M, Martin-Padura I, Hersberger M, et al. Genetic deletion of p66(Shc) adaptor protein prevents hyperglycemia-induced endothelial dysfunction and oxidative stress. Proc Natl Acad Sci U S A. 2007;104:5217-22.

41. Migliaccio E, Giorgio M, Mele S, Pelicci G, Reboldi P, Pandolfi PP, et al. The p66shc adaptor protein controls oxidative stress response and life span in mammals. Nature. 1999;402:309-13.

42. Giorgio M, Migliaccio E, Orsini F, Paolucci D, Moroni M, Contursi $\mathrm{C}$, et al. Electron transfer between cytochrome $\mathrm{c}$ and p66Shc generates reactive oxygen species that trigger mitochondrial apoptosis. Cell. 2005;122:221-33.

43. Shi Y, Cosentino F, Camici GG, Akhmedov A, Vanhoutte PM, Tanner FC, et al. Oxidized low-density lipoprotein activates p66Shc via lectin-like oxidized low-density lipoprotein receptor-1, protein kinase C-beta, and c-Jun N-terminal kinase kinase in human endothelial cells. Arterioscler Thromb Vasc Biol. 2011;31:2090-7.

44. Ranieri SC, Fusco S, Pani G. p66(ShcA): linking mammalian longevity with obesity-induced insulin resistance. Vitam Horm. 2013;91:219-41.

45. Rajapakse AG, Yepuri G, Carvas JM, Stein S, Matter CM, Scerri I, et al. Hyperactive S6K1 mediates oxidative stress and endothelial dysfunction in aging: inhibition by resveratrol. PLoS One. 2011;6:e19237.

46. Rota M, LeCapitaine N, Hosoda T, Boni A, De Angelis A, PadinIruegas $\mathrm{ME}$, et al. Diabetes promotes cardiac stem cell aging and 
heart failure, which are prevented by deletion of the p66shc gene. Circ Res. 2006;99:42-52.

47. Paneni F, Mocharla P, Akhmedov A, Costantino S, Osto E, Volpe M, et al. Gene silencing of the mitochondrial adaptor p66(Shc) suppresses vascular hyperglycemic memory in diabetes. Circ Res. 2012;111:278-89.

48. Pagnin E, Fadini G, de Toni R, Tiengo A, Calo L, Avogaro A. Diabetes induces p66shc gene expression in human peripheral blood mononuclear cells: relationship to oxidative stress. J Clin Endocrinol Metab. 2005;90:1130-6.

49. Franzeck FC, Hof D, Spescha RD, Hasun M, Akhmedov A, Steffel J, et al. Expression of the aging gene p66Shc is increased in peripheral blood monocytes of patients with acute coronary syndrome but not with stable coronary artery disease. Atherosclerosis. 2012;220:2826.

50. Pandolfi S, Bonafe M, Di Tella L, Tiberi L, Salvioli S, Monti D, et al. p66(shc) is highly expressed in fibroblasts from centenarians. Mech Ageing Dev. 2005;126:839-44.

51. Paneni F, Cosentino F. p66 Shc as the engine of vascular aging. Curr Vasc Pharmacol. 2012;10:697-9.

52. Gerald D, Berra E, Frapart YM, Chan DA, Giaccia AJ, Mansuy D, et al. JunD reduces tumor angiogenesis by protecting cells from oxidative stress. Cell. 2004;118:781-94.

53. Mechta-Grigoriou F, Gerald D, Yaniv M. The mammalian Jun proteins: redundancy and specificity. Oncogene. 2001;20:2378-89.

54. Hernandez JM, Floyd DH, Weilbaecher KN, Green PL, Boris-Lawrie $\mathrm{K}$. Multiple facets of junD gene expression are atypical among AP-1 family members. Oncogene. 2008;27:4757-67.

55. Chen CH, Budas GR, Churchill EN, Disatnik MH, Hurley TD, Mochly-Rosen D. Activation of aldehyde dehydrogenase-2 reduces ischemic damage to the heart. Science. 2008;321:1493-5.

56. Koda K, Salazar-Rodriguez M, Corti F, Chan NY, Estephan R, Silver $\mathrm{RB}$, et al. Aldehyde dehydrogenase activation prevents reperfusion arrhythmias by inhibiting local renin release from cardiac mast cells. Circulation. 2010;122:771-81.

57. Srinivasan S, Hatley ME, Bolick DT, Palmer LA, Edelstein D, Brownlee $\mathrm{M}$, et al. Hyperglycaemia-induced superoxide production decreases eNOS expression via AP-1 activation in aortic endothelial cells. Diabetologia. 2004;47:1727-34.

58. Ricci R, Eriksson U, Oudit GY, Eferl R, Akhmedov A, Sumara I, et al. Distinct functions of junD in cardiac hypertrophy and heart failure. Genes Dev. 2005;19:208-13.

59. Hilfiker-Kleiner D, Hilfiker A, Kaminski K, Schaefer A, Park JK, Michel K, et al. Lack of JunD promotes pressure overload-induced apoptosis, hypertrophic growth, and angiogenesis in the heart. Circulation. 2005;112:1470-7.

60. Corbi G, Conti V, Scapagnini G, Filippelli A, Ferrara N. Role of sirtuins, calorie restriction and physical activity in aging. Front Biosci (Elite Ed). 2012;4:768-78.

61. Hall JA, Dominy JE, Lee Y, Puigserver P. The sirtuin family's role in aging and age-associated pathologies. J Clin Invest. 2013;123:973-9.

62. Sundaresan NR, Pillai VB, Gupta MP. Emerging roles of SIRT1 deacetylase in regulating cardiomyocyte survival and hypertrophy. $\mathrm{J}$ Mol Cell Cardiol. 2011;51:614-8.

63. Paneni F, Volpe M, Luscher TF, Cosentino F. SIRT1, p66Shc, and Set7/9 in vascular hyperglycemic memory: bringing all the strands together. Diabetes. 2013;62:1800-7.

64. Zhang QJ, Wang Z, Chen HZ, Zhou S, Zheng W, Liu G, et al. Endothelium-specific overexpression of class III deacetylase SIRT1 decreases atherosclerosis in apolipoprotein E-deficient mice. Cardiovasc Res. 2008;80:191-9.

65. Stein S, Lohmann C, Schafer N, Hofmann J, Rohrer L, Besler C, et al. SIRT1 decreases Lox-1-mediated foam cell formation in atherogenesis. Eur Heart J. 2010;31:2301-9.

66. Ota H, Eto M, Ako J, Ogawa S, Iijima K, Akishita M, et al. Sirolimus and everolimus induce endothelial cellular senescence via sirtuin 1 down-regulation: therapeutic implication of cilostazol after drugeluting stent implantation. J Am Coll Cardiol. 2009;53:2298-305.

67. - Zhou S, Chen HZ, Wan YZ, Zhang QJ, Wei YS, Huang S, et al. Repression of P66Shc expression by SIRT1 contributes to the prevention of hyperglycemia-induced endothelial dysfunction. Circ Res. 2011;109:639-48. This work provides an interesting molecular connection between SIRT1 and $p 66^{\text {Shc }}$. The paper shows that $p 66^{\text {Shc }}$ is epigenetically regulated by deacetylase SIRT1 in the vascular endothelium. This mechanistic finding implies an intricate cross talk between aging and longevity genes.

68. Cevenini E, Monti D, Franceschi C. Inflamm-ageing. Curr Opin Clin Nutr Metab Care. 2013;16:14-20.

69. •• Hasegawa Y, Saito T, Ogihara T, Ishigaki Y, Yamada T, Imai J, et al. Blockade of the nuclear factor-kappaB pathway in the endothelium prevents insulin resistance and prolongs life spans. Circulation. 2012;125:1122-33. The article shows that the transcription factor $N F-k B$ is critically involved in endothelial insulin resistance. Suppression of NF- $k B$ signalling in the endothelium results in improved insulin signalling in other organs as well as improved lifespan in mice. These novel findings suggest that $N F-k B$ is a key molecular intermediate linking metabolic disease, inflammation and aging.

70. Baker RG, Hayden MS, Ghosh S. NF-kappaB, inflammation, and metabolic disease. Cell Metab. 2011;13:11-22.

71. Donato AJ, Pierce GL, Lesniewski LA, Seals DR. Role of NFkappaB in age-related vascular endothelial dysfunction in humans. Aging (Albany NY). 2009;1:678-80.

72. Gupta S, Young D, Maitra RK, Gupta A, Popovic ZB, Yong SL, et al. Prevention of cardiac hypertrophy and heart failure by silencing of NF-kappaB. J Mol Biol. 2008;375:637-49.

73. Lahteenvuo J, Rosenzweig A. Effects of aging on angiogenesis. Circ Res. 2012;110:1252-64.

74. Williamson K, Stringer SE, Alexander MY. Endothelial progenitor cells enter the aging arena. Front Physiol. 2012;3:30.

75. Dzau VJ, Gnecchi M, Pachori AS, Morello F, Melo LG. Therapeutic potential of endothelial progenitor cells in cardiovascular diseases. Hypertension. 2005;46:7-18.

76. Templin C, Krankel N, Luscher TF, Landmesser U. Stem cells in cardiovascular regeneration: from preservation of endogenous repair to future cardiovascular therapies. Curr Pharm Des. 2011;17:3280 94.

77. Keymel S, Kalka C, Rassaf T, Yeghiazarians Y, Kelm M, Heiss C. Impaired endothelial progenitor cell function predicts age-dependent carotid intimal thickening. Basic Res Cardiol. 2008;103:582-6.

78. Hoenig MR, Bianchi C, Rosenzweig A, Sellke FW. Decreased vascular repair and neovascularization with ageing: mechanisms and clinical relevance with an emphasis on hypoxia-inducible factor-1. Curr Mol Med. 2008;8:754-67.

79. Giannotti G, Doerries C, Mocharla PS, Mueller MF, Bahlmann FH, Horvath $\mathrm{T}$, et al. Impaired endothelial repair capacity of early endothelial progenitor cells in prehypertension: relation to endothelial dysfunction. Hypertension. 2010;55:1389-97.

80. Fadini GP, Albiero M, Fadini GP, Albiero M, Vigili de Kreutzenberg $\mathrm{S}$, Boscaro E, et al. Diabetes impairs stem cell and proangiogenic cell mobilization in humans. Diabetes Care. 2013;36:943-9.

81. Di Stefano V, Cencioni C, Zaccagnini G, Magenta A, Capogrossi MC, Martelli F. p66ShcA modulates oxidative stress and survival of endothelial progenitor cells in response to high glucose. Cardiovasc Res. 2009;82:421-9.

82. Liang R, Bates DJ, Wang E. Epigenetic control of MicroRNA expression and aging. Curr Genomics. 2009;10:184-93.

83. Anand S. A brief primer on microRNAs and their roles in angiogenesis. Vasc Cell. 2013;5:2.

84. Quiat D, Olson EN. MicroRNAs in cardiovascular disease: from pathogenesis to prevention and treatment. J Clin Invest. 2013;123:11-8.

85. ••Zhu S, Deng S, Ma Q, Zhang T, Jia C, Zhuo D, et al. MicroRNA$10 A^{*}$ and MicroRNA-21 modulate endothelial progenitor cell 
senescence via suppressing high-mobility group A2. Circ Res. 2013;112:152-64. This study demonstrates that miR-10A* and miR-21, and their common target gene Hmga2 are critical regulators of EPCs senescence. Suppression of miR-10A* and miR-21 in aged EPCs increased Hmga2 expression and rejuvenated EPCs, thus improving angiogenesis. These findings strongly suggest the possibility of reprogramming pivotal microRNAs in order to improve EPCs functionality in aging.

86. Zhao T, Li J, Chen AF. MicroRNA-34a induces endothelial progenitor cell senescence and impedes its angiogenesis via suppressing silent information regulator 1. Am J Physiol Endocrinol Metab. 2010;299:E110-6.

87. Jakob P, Doerries C, Briand S, Mocharla P, Krankel N, Besler C, et al. Loss of angiomiR-126 and 130a in angiogenic early outgrowth cells from patients with chronic heart failure: role for impaired in vivo neovascularization and cardiac repair capacity. Circulation. 2012;126:2962-75.

88. Surder D, Manka R, Lo Cicero V, Moccetti T, Rufibach K, Soncin S, et al. Intracoronary injection of bone marrow-derived mononuclear cells early or late after acute myocardial infarction: effects on global left ventricular function. Circulation. 2013;127:1968-79.
89. Zhang H, Wang H, Li N, Duan CE, Yang YJ. Cardiac progenitor/ stem cells on myocardial infarction or ischemic heart disease: what we have known from current research. Heart Fail Rev. 2013. doi:10. 1007/s10741-013-9372-0.

90. Hou J, Wang L, Jiang J, Zhou C, Guo T, Zheng S, et al. Cardiac stem cells and their roles in myocardial infarction. Stem Cell Rev. 2013;9: 326-38.

91. Boudina S. Cardiac aging and insulin resistance: could insulin/ insulin-like growth factor (IGF) signaling be used as a therapeutic target? Curr Pharm Des. 2013;CPD-EPUB-20130220-14.

92. D'Amario D, Cabral-Da-Silva MC, Zheng H, Fiorini C, Goichberg P, Steadman E, et al. Insulin-like growth factor-1 receptor identifies a pool of human cardiac stem cells with superior therapeutic potential for myocardial regeneration. Circ Res. 2011;108:1467-81.

93. Cesselli D, Beltrami AP, D'Aurizio F, Marcon P, Bergamin N, Toffoletto B, et al. Effects of age and heart failure on human cardiac stem cell function. Am J Pathol. 2011;179:349-66.

94. Bolli R, Chugh AR, D'Amario D, Loughran JH, Stoddard MF, Ikram $\mathrm{S}$, et al. Cardiac stem cells in patients with ischaemic cardiomyopathy (SCIPIO): initial results of a randomised phase 1 trial. Lancet. 2011;378:1847-57. 